\title{
Frequency of Hepatitis C in Multiple Transfused Children at Sir Ganga Ram Hospital (S.G.R.H) Lahore, Pakistan
}

Anam Yousaf*, Nawaz chaudhry, Abdul Qadir, and Aqeel Ahmad

Department of Oncology and thalassemia center, Fatima Jinnah Medical College and Sir Ganga Ram Hospital, University of the Punjab, Lahore, Pakistan

\begin{abstract}
Background: Viral hepatitis is a global issue. Among hepatic viruses (HBV) and (HCV) are important in South Asia including Pakistan. There are various modes of transmission of these viruses but vertical transmission is gaining importance day by day. Screening of (HCV) would help to reduce the prevalence of Anti-HCV among multiple transfused children. Proper antiviral therapy and screening of blood before transfusion can help to reduce the prevalence of (HCV).

Methods: This study was a detailed, observational study carried out using non probability purposive sampling technique. The period of the study was from November 2009 to June 2011. 200 multiple transfused children attended outdoor department and indoor thalassemic children from thalassemia center were included. Informed consent was taken. A specially designed proforma was filled by parents to collect data about their knowledge and awareness regarding (HCV). Anti- HCV was tested by Enzyme Linked Immunosorbent Assay (ELISA) method. Data were statistically analyzed by DSAASTAT (Onofri, Italy).
\end{abstract}

Results: current investigation concluded that children with ages 12 years and more were maximum $(\mathrm{HCV})$ reactive (31\%) between 4 - 8 years (22\%) 6 months - 2 years (19\%) 2- 4 years $(15 \%)$ and $8-12$ years were $(12 \%)$. Male children were reported $61 \%$ and female were $39 \%$. Study concluded that total number of thalassemia children were 180 , children with different types of leukemia were 10, aplastic anemia were 6 , neuroblastoma were 2 , while 1 each with thrombasthenia and CDA type-1. Out of 180 thalassemic children $(24.4 \%)$ were reactive and $(75.5 \%)$ non-reactive $(100 \%)$ cases were reactive in Leukemia. Therefore, $(16.6 \%)$ reactive and $(83.3 \%)$ nonreactive cases were reported in aplastic anemia. Children with neuroblastoma, thrombasthenia and CDA type-1 were (100\%) non-reactive. Maximum $(\mathrm{HCV})$ reactive cases reported in Thalassemia children and most of them were belongs to rural area, exposed to poor socioeconomic status.

Conclusion: Frequency of (HCV) was higher in population living in southern region of Pakistan. Previous history of blood transfusion, multiple injection therapy and unsterilized surgery were observed as key risk factors in (HCV) prevalence.

Keywords: HCV (Hepatitis C virus), Enzyme linked immunosorbent assay (ELISA), HBsAg (Hepatitis B surface antigen), World health organization (WHO), CDA type-1 (Congenital dyserythropoitic anemia).

\section{Introduction}

According to WHO 12-15 million children are being infected each year. In Pakistan the situation is not different from rest of the world. Among hepatitis viruses, $(\mathrm{HCV})$ gained much importance due to high prevalence which needs extensive studies. Recently, Pakistan Medical Research Council (PMRC) has conducted a national survey on prevalence of $(\mathrm{HCV})$ in general population of Pakistan. The preliminary reports revealed that $(\mathrm{HCV})$ is reactive in $4.9 \%$ of population. According to this survey about 12 million population of Pakistan is affected by (HCV) [1]. However, another study reported prevalence of (HBsAg) $2.5 \%$ and $(\mathrm{HCV}) 5.3 \%$ [2]. It is evident from epidemiological studies that the virus is mainly transmitted through parenteral route [3]. The transmission risk of the virus increases among persons who are given unsterilized therapeutic injections, sharing of infected needles among IV (intravenous) drug abusers, having transfusion of contaminated blood, patients on hemodialysis, having unsafe sex, sharing of items like toothbrushes miswaks, razors and infected combs, having dental procedure with infected instruments having endoscopies with unsterilized instruments, self-infliction as a part of religious activity (maatam) with infected chains and persons who have their faces or armpits shaved by street barbers [4]. The cosmetic alterations like body piercing or tattooing done by unsterilized needles and use of infected tweezers, reuse of sponge for skin treatments in saloons, sharing of nose pins are becoming major threats for transmission of (HCV).

(HCV) also transmitted sexually described in previous studies [3]. Sexual transmission of (HBV) is more pronounced. In USA the heterosexual transmission of (HBV) accounts 39\% among the new HBV infections in adults [5] and (HCV) also transmitted sexually however prevalence is much less as compared to (HBV) [6]. HCV screening of blood products introduced in various countries has minimized the risk of transmission through blood transfusion. The risk of transmission of (HCV) from viremic (HCV) RNA positive mothers to their infants is $3.2 \%$ and transmission risk further increases if the mother is co-infected with HIV to 7.9\% [7]. Both these viruses can lead to chronic hepatitis, cirrhosis and hepatocellular carcinoma [8].

The possibility of vertical transmission highlights the importance to diagnose the acute and chronic hepatic viral infections in multiple

*Corresponding author: Anam Yousaf, Department of Oncology and thalassemia center, Fatima Jinnah Medical College and Sir Ganga Ram Hospital, University of the Punjab, Lahore, Pakistan, Tel: +92 322414 7507; E-mail: anam287@yahoo.com

Received February 04, 2015; Accepted April 21, 2015; Published April 28, 2015

Citation: Yousaf A, chaudhry N, Qadir A, Ahmad A (2015) Frequency of Hepatitis C in Multiple Transfused Children at Sir Ganga Ram Hospital (S.G.R.H) Lahore, Pakistan. J Trop Dis 3: 156. doi:10.4172/2329891X.1000156

Copyright: (C) 2015 Yousaf A This is an open-access article distributed under the terms of the Creative Commons Attribution License, which permits unrestricted use, distribution, and reproduction in any medium, provided the original author and source are credited. 
transfused children thereby justifying mandatory antepartum screening for (HCV). It has benefits making it possible to refer these infected children for appropriate antiviral therapy at appropriate time and before the development of significant liver damage. Present study was designed to determine the frequency of (HCV) in multiple transfused children at Sir Ganga Ram Hospital, Lahore. The results of proposed study would provide some data for the future in-depth studies on this vital subject.

\section{Material and Methods}

This cross sectional study was carried out at outdoor department of oncology and indoor department of thalassemia center at, Sir Ganga Ram Hospital Lahore, a tertiary care hospital. The study was carried out from November 2009 to June 2011. A total 200 multiple transfused children of thalassemia center and oncology outpatient department were included in this study. Informed consent was taken; especially designed proforma was filled to collect the questionnaires data. (HCV) screening was tested by (ELISA) method and data were statistically analyzed through ANOVA and DMRT at $\mathrm{p} \leq 0.05$ using DSAASTAT (Onofri, Italy).

\section{Results}

Current investigation concluded that children with ages 12 years and more were maximum (31\%) between $4-8$ years (22\%) 6 months - 2 years (19\%) 2-4 years (15\%) and 8-12 years are (12\%). Maximum number of children was between ages 12 years and more [Table 1] Figure 1. Study showed male children were $61 \%$ and female were $39 \%$ [Table 2] Figure 2.

Total number of thalassemia children was 180 and children with different types of leukemia were 10 while children with aplastic anemia were 6 , two children were with neuroblastoma while one each with thrombasthenia and CDA type-1. Out of 180 thalassemia children $(24.4 \%)$ were reactive and $(75.5 \%)$ were nonreactive. In Leukemic children $(100 \%)$ were nonreactive; in aplastic anemia (16.6\%) were reactive and $(83.3 \%)$ were nonreactive. Children with neuroblastoma, thrombasthenia and CDA type-1 (100\%) were nonreactive [Table 3] Figure 3. Maximum (HCV) reactive cases were reported in thalassemia children and most of them were belongs to rural areas with poor socioeconomic status. Majority of children included in current study were suffering from thalassemia that showed high frequency of (HCV) $24.5 \%$ among other children. Patients with aplastic anemia were at the second place showing $16.6 \%$ frequency. Other multiple transfused diseases have reported less nonreactive cases.

Number of blood transfusion was also a major risk factor for (HCV) prevalence and current study revealed that number of 85 children had more than 25 sessions of blood transfusion while 59 children had 2650 transfusions, number of 23 children had 51-100 transfusions while 33 children received more than 100 transfusions, (2.4\%) were reactive, (97.6\%) were nonreactive. Out of 59 children received 26-50 times transfusion, $(6.8 \%)$ were reactive $(93.2 \%)$ were nonreactive. Out of 23

\begin{tabular}{|c|r|c|}
\hline Sr \# & Age (Year) & Percentage (\%) \\
\hline $\mathbf{1}$ & $6 \mathrm{~m}-2$ & 19 \\
\hline $\mathbf{2}$ & $2-4$ & 15 \\
\hline $\mathbf{3}$ & $4-8$ & 22 \\
\hline $\mathbf{4}$ & $8-12$ & 12 \\
\hline $\mathbf{5}$ & $\geq 12$ & 31 \\
\hline
\end{tabular}

Table 1: Number of multiple blood transfusions according to age.

\section{Age distribution of children with multiple Transfusions}

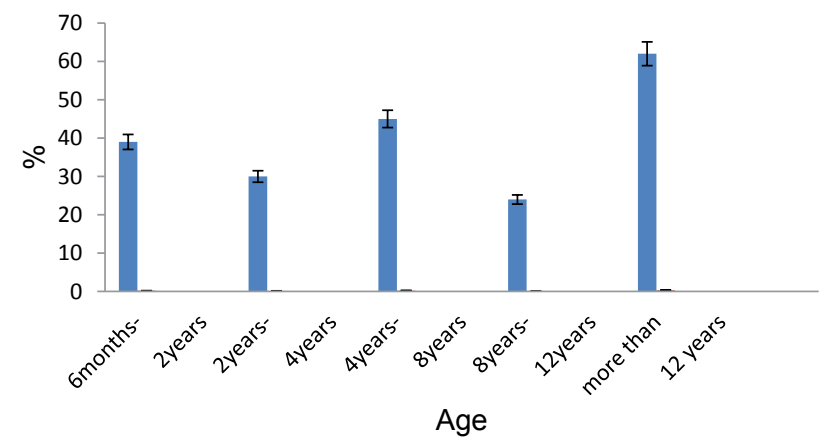

Figure 1: Percentage change in Age distribution of children with multiple transfusions. Data were statistically analysed through ANOVA and DMRT at $p \leq 0.05$ using DSAASTAT (Onofri, Italy). Error bars show the standard error calculated against each bar and significance of data has been mentioned through alphabets (e.g. a, b, c......) calculated at $p \leq 0.05$.

\begin{tabular}{|c|c|c|c|}
\hline Sr\# & Gender & & Percentage (\%) \\
\hline $\mathbf{1}$ & male & 61 \\
\hline $\mathbf{2}$ & female & 39 \\
\hline
\end{tabular}

Table 2: Number of multiple blood transfusions according to gender.

\section{number of blood transfusions according to gender}

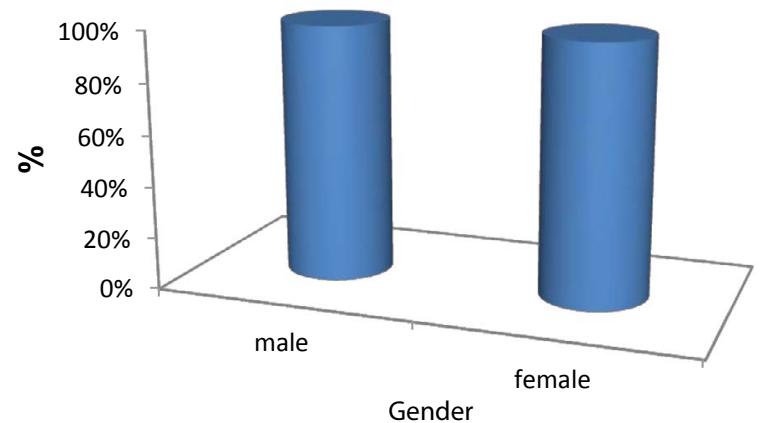

Figure 2: Percentage change in gender distribution of children with multiple transfusions. Data were statistically analysed through ANOVA and DMRT at $\mathrm{p} \leq 0.05$ using DSAASTAT (Onofri, Italy).

children with 51-100 transfusions, (35.0\%) were reactive (65.2\%) were nonreactive. Number of 33 children with more than 100 transfusions reported $(88.0 \%)$ reactive cases and $(12.0 \%)$ nonreactive. (HCV) prevalence was directly related to the number of transfusions as shown in [Table 4]. Figure 4 indicated the $\%$ age reactivity according to the number of blood transfusions received by children.

Total number of cases studied were 200 out of $(22.5 \%)$ was reactive with multiple transfusions and (77.5\%) were nonreactive [Table 5] Figure 5. According to the number of blood transfusions frequency of HCV was recorded maximum in thalassemia children then in aplastic anemia.

\section{Discussion}

(HCV) is the major concern throughout the world and being 
Citation: Yousaf A, chaudhry N, Qadir A, Ahmad A (2015) Frequency of Hepatitis C in Multiple Transfused Children at Sir Ganga Ram Hospital (S.G.R.H) Lahore, Pakistan. J Trop Dis 3: 156. doi:10.4172/2329891X.1000156

\begin{tabular}{|c|c|c|c|}
\hline Sr \# & Diseases & Reactive cases (\%) & Non- Reactive cases (\%) \\
\hline $\mathbf{1}$ & Thalassemia & 24.4 & 75.5 \\
\hline $\mathbf{2}$ & Leukemia & 0.0 & 10 \\
\hline $\mathbf{3}$ & Aplastic Anemia & 16.6 & 83.3 \\
\hline $\mathbf{4}$ & Neuroblastoma & 0.0 & 2.0 \\
\hline $\mathbf{5}$ & Thrombasthenia & 0.0 & 1.0 \\
\hline $\mathbf{6}$ & CDA type 1 & 0.0 & 1.0 \\
\hline
\end{tabular}

Table 3: Frequency of reactive and nonreactive cases in different disease categories of multiple transfused children.

\section{Frequency of Seropositivity in different disease categories of multiple Transfused Children}

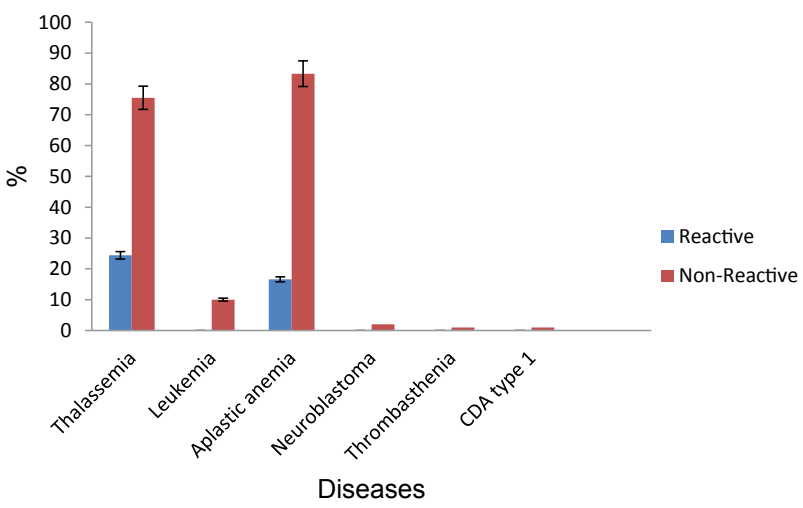

Figure 3: Percentage change in frequency of reactive and nonreactive cases in different disease categories with multiple transfusions. Data were statistically analysed through ANOVA and DMRT at $p \leq 0.05$ using DSAASTAT (Onofri, Italy). Error bars show the standard error calculated against each bar and significance of data has been mentioned through alphabets (e.g. a, b, c......) calculated at $p \leq 0.05$.

\begin{tabular}{|c|c|c|c|}
\hline Sr \# & $\begin{array}{c}\text { No. of } \\
\text { Transfusions }\end{array}$ & $\begin{array}{c}\text { Reactive cases } \\
\text { (\%) }\end{array}$ & $\begin{array}{c}\text { Non- Reactive } \\
\text { cases (\%) }\end{array}$ \\
\hline $\mathbf{1}$ & $2-25$ & 2.4 & 97.6 \\
\hline $\mathbf{2}$ & $26-50$ & 6.8 & 93.2 \\
\hline $\mathbf{3}$ & $51-100$ & 35.0 & 65.2 \\
\hline $\mathbf{4}$ & $\geq 100$ & 88.0 & 12.0 \\
\hline
\end{tabular}

Table 4: Frequency of reactive and nonreactive cases according to number of blood transfusions.

extensively studied. Worldwide many studies have been conducted to determine the frequency of (HCV) in their general population, in healthy blood donors and in different age groups. Proposed study on multiple transfused children was also designed to determine the frequency of (HCV) patients in Pakistan. Data from questionnaires concluded alarming situation due to lack of awareness and poor socioeconomic status. (HCV) is prevailing more rapidly among developing countries than developed countries due to poor hygienic conditions within the hospitals and blood transfusion centers. Current investigation revealed (HCV) reactivity were $22.5 \%$ out of 200 children and $77.5 \%$ nonreactive. (HCV) reactivity are comparable with the studies conducted by [9] and [10] reported low frequency that may be due to the fact it was conducted in people who were educated and having better socioeconomic status and were health conscious as well as aware of hepatitis infections. All (HCV) reactive children were exposed to multiple transfusions and most of them belong to rural areas with poor socioeconomic status.

Study concluded that previous history of blood transfusion is a major risk factor for the transmission of (HCV). Multiple injection use was also observed as leading risk factor and it has also been supported by [11]. Prevalence of (HCV) is increasing day by day among people of Pakistan due to poor hygienic and environmental conditions and the major threat is for multiple transfused children. Because they do not have enough resources to obtain screened blood due to poverty and lack of awareness.

Multiple blood transfusions have direct relation to $(\mathrm{HCV})$ transmission, as reported in the study those children who took more than 100 blood transfusions had maximum number of reactive cases.

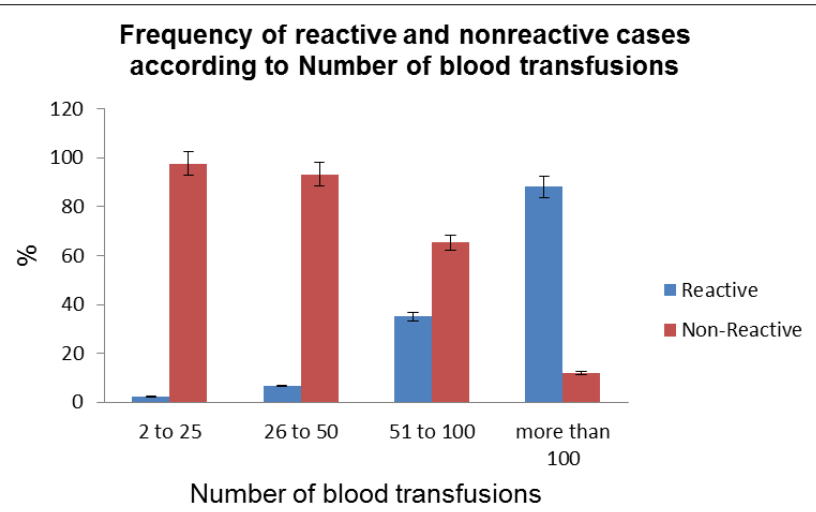

Figure 4: Percentage change in frequency of reactive and nonreactive cases according to number of blood transfusions. Data were statistically analysed through ANOVA and DMRT at $p \leq 0.05$ using DSAASTAT (Onofri , Italy). Error bars show the standard error calculated against each bar and significance of data has been mentioned through alphabets (e.g. a, b, c......) calculated at $p \leq 0.05$.

\begin{tabular}{|l|c|c|l|}
\hline Sr \# & Reactive (\%) & Nonreactive (\%) \\
\hline 1 & 22.5 & 77.5 \\
\hline
\end{tabular}

Table 5: Reactive and nonreactive cases in children with multiple blood transfusions

Reactive and nonreactive cases in children with multiple blood transfusions

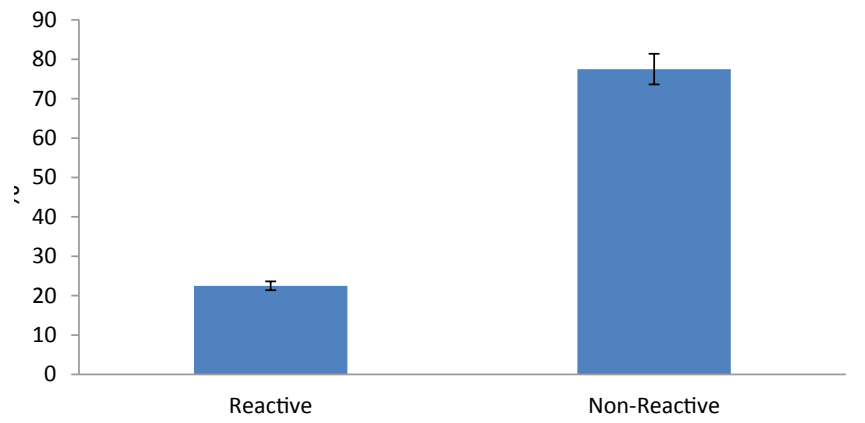

Figure 5: Percentage change in frequency of reactive and nonreactive cases in children with multiple blood transfusions. Data were statistically analysed through ANOVA and DMRT at $p \leq 0.05$ using DSAASTAT (Onofri, Italy). Error bars show the standard error calculated against each bar and significance of data has been mentioned through alphabets (e.g. a, b, c......) calculated at $p \leq 0.05$. 
Citation: Yousaf A, chaudhry N, Qadir A, Ahmad A (2015) Frequency of Hepatitis C in Multiple Transfused Children at Sir Ganga Ram Hospital (S.G.R.H) Lahore, Pakistan. J Trop Dis 3: 156. doi:10.4172/2329891X.1000156

Page 4 of 4

According to statistics in Pakistan indicated the maximum frequency of $(\mathrm{HCV})$ reported in patients exposed to greater number of blood transfusions as compare to less number of blood transfusions. This was indicated as well in the current study that frequency of (HCV) was not directly related to the type of disease but actually with the number of blood transfusions.

200 total number of samples were collected and out of 200 (22.5\%) were reactive with multiple transfusions and $(77.5 \%)$ were nonreactive. Maximum number of reactive cases was recorded in thalassemia children with insignificant difference with aplastic anemia.

\section{Conclusion}

Frequency of (HCV) was recorded maximum in proposed study population, $22.5 \%$ children were reactive and $77.5 \%$ were nonreactive. Thalassemia children reported maximum (HCV) reactivity and $24.4 \%$ as compared to other disease categories. (HCV) reactivity was maximum in Children who exposed to more than 100 blood transfusions. Chances of (HCV) transmission increases as the number of blood transfusions increased. Previous history of blood transfusion, multiple injection therapy and surgery were observed as leading risk factors among (HCV) reactive multiple transfused children. Study have showed that prevalence of $(\mathrm{HCV})$ were more common in thalassemia children, because of multiple transfusions and unavailability of healthy blood. There was no separate blood bank for thalassemia children. Besides, education and socioeconomic status also contribute as an important factor in prevalence of (HCV).

\section{Acknowledgements}

I am thankful to Prof. Dr. Nawaz Muhammad Chaudhry, emeritus supervisor, University of the Punjab Lahore for his kind assistance throughout the study.

\section{References}

1. National Survey on prevalence of Hepatitis B \& C in general population of Pakistan (2007) Pakistan Medical Research Council.

2. Khokhar N, Gill ML, Malik GJ (2004) General Seroprevalence of Hepatitis $\mathrm{C}$ and $\mathrm{B}$ virus infection in population. J Coll Physicians Surg Pak. Vol. 14: 534-536.

3. Sherlock S, Dooley J (2002) Diseases of the liver and biliary system 11thedtn, Vol. 11, pp. 307-308.

4. Sherlock S, Dooley J (2002) Diseases of the liver and biliary system 11thedtn, Vol. 11, pp. 290.

5. Mast EE, Weinbaum CM, Fiore AE, Alter MJ et al. (2006) A comprehensive immunization strategy to eliminate transmission of hepatitis $B$ virus infection in the United States. Recommendations and Reports. Vol. 55: 1-25.

6. Vandelli C, Renzo F, Romano L, Tisminetzky S et al. (2004) Lack of evidence of sexual transmission of hepatitis $C$ among monogamous couples, results of a 10 year prospective follow-up study. Am J Gastroenterol. Vol. 99: 855-859.

7. Davis GL (2007) Hepatitis C in Schiff's diseases of the liver, Philadelphia Lippincott Williams and Wilkins Vol. 10: 807-863.

8. Kumar A, Sharma KA, Gupta RK, Chakarvati A et al. (2007) Prevalence \& risk factors for hepatitis $C$ virus among pregnant women. Indian J Med Res. Vol. 126: 211-215.

9. Batool A, Bano K A, Khan M I, Hussain R (2008) Antenatal screening of women for hepatitis $B$ and $C$ in an outpatient department. Journal of Dow University Health Sciences Vol. 1: 32-35.

10. Zafar MA, Mohsin A, Hussain I, Shah AA (2001) Prevalence of hepatitis C among pregnant women. J Surg Pak. Vol. 2: 32-33.

11. Idrees M, Lal A, Naseem M, Khalid M (2008) High prevalence of hepatitis C virus infection in largest province of Pakistan. J Dig Dis. Vol. 9: 95-103. 